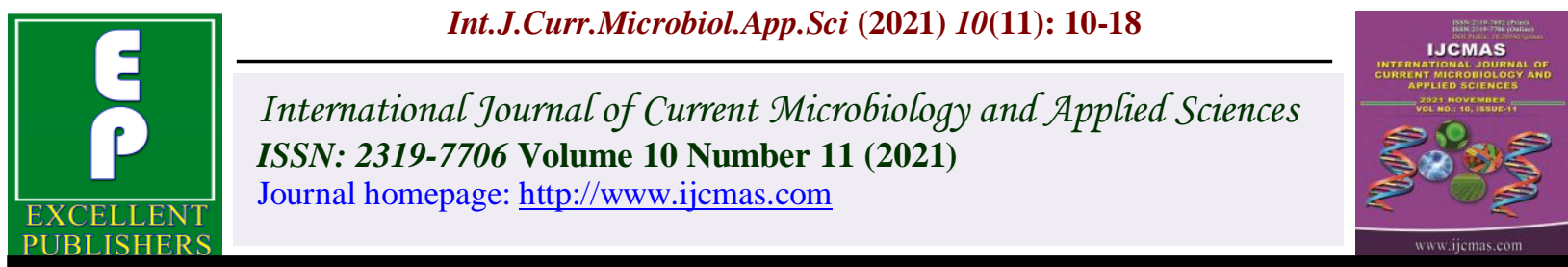

\title{
Microbial Profile and Antibiogram of Ventilator Associated Pneumonia at Tertiary Care Hospital U.P
}

\author{
Anil Singh Yadav ${ }^{1}$, R. Sujatha ${ }^{2}$, Dilshad Khan ${ }^{3 *}$, Dilshad Arif ${ }^{1}$ and Astha Gupta ${ }^{4}$ \\ ${ }^{1}$ Department of Microbiology, Government Medical College \& Super Facility Hospital, \\ Azamgarh, U.P. India \\ ${ }^{2}$ Department of Microbiology, Rama Medical College Hospital \& Research Centre Kanpur, \\ U.P. India \\ ${ }^{3}$ Department of Microbiology, Government Medical College. Banda, U.P. India \\ ${ }^{4}$ Department of Microbiology, Government Medical College. Orai, U.P. India \\ *Corresponding author
}

A B S T R A C T

Keywords

Ventilator-

associated

pneumonia,

MRSA,

Pseudomonas

aeruginosa

Article Info

Received:

03 October 2021

Accepted:

29 October 2021

Available Online:

10 November 2021
Ventilator associated pneumonia (VAP) is a common and serious healthcare associated infection (HAI). VAP is inflammation of lung parenchyma caused by infectious agents that develops in a patient who is on a ventilator occurring 48-72 hrs or more after tracheal intubation and mechanical ventilation (MV). The risk of VAP is highest early in the course of hospital stay, and is estimated to be $3 \% /$ day during the first 5 days of ventilation, $2 \%$ /day during days 5-10 of ventilation and $1 \%$ /day after this. Aim of this study was find out the Microbial profile and antibiogram of ventilator associated pneumonia at tertiary care hospital U.P. This study was conducted in the Department of Microbiology, Rama Medical College, Hospital \& Research Centre, Kanpur India from January 2016 to December 2016. A total of 100 Endotracheal aspirated samples were collected in a sterile \& labelled clean dry container from the clinically suspected cases of VAP patients. Out of 100 patients 31 patients shown growth of the bacteria \& considered as Ventilator Associated Pneumonia patients. And 69 patients have not shown any kind of growth. Acinetobacter baumanni, Pseudomonas aeruginosa, Enterobacter \& Klebsiella Pneumoniae were the most common pathogens from both early \& late onset VAP. Proper monitoring and strict implementation of infection control practices is very essential to reduce VAP in hospital setting. Also the short term use of invasive devices and judicious use of antibiotics are important in preventing VAP caused by these MDR pathogens.

\section{Introduction}

Ventilator-associated pneumonia (VAP) is a lung infection that develops in a person who is on ventilator. It is a common infectious disease that is found in intensive care unit (ICU). ${ }^{(1)}$ A ventilator is a machine that is used to help a patient breathe by giving oxygen 
through a tube placed in a patient's mouth or nose, or through a hole in the front of the neck. An infection may occur if germs enter through the tube and get into the patient's lungs parenchyma. Infectious agents that develops in a patient who is on a ventilator occurring 48-72 hrs or more after tracheal intubation and mechanical ventilation (MV). ${ }^{(2,3)}$ Intubation independently increases the risk of the developing pneumonia. It is the most common hospital associated infection accounting for $9-28 \%$ of all incubated patients. ${ }^{(4)}$ Ventilator associated pneumonia may be of early onset and late onset. Early onset Ventilator associated pneumonia, defined as occurring within the first four days of hospitalization, usually carry a better prognosis, and is more likely to be caused by antibiotic-sensitive bacteria. Late onset Ventilator associated pneumonia when it develops five or more days and more likely to be caused by multidrug-resistant (MDR) pathogens, and are associated with increased patient mortality and morbidity. ${ }^{(2)}$ Early-onset nosocomial pneumonia was believed due to primarily gram-negative bacteria, such as Haemophilus influenzae, and Methicillinsensitive Staphylococcus aureus (MSSA) and Streptococcus pneumoniae.

For late-onset nosocomial pneumonia causative pathogens reported were higherlevel antibiotic-resistant gram-negative bacteria, such as Pseudomonas aeruginosa, Acinetobacter spp and Methicillin-resistant $S$. aureus (MRSA). ${ }^{(5)}$ Mechanically ventilated patients are at high risk for complications and poor outcomes, including death. Ventilatorassociated pneumonia (VAP), sepsis, Acute Respiratory Distress Syndrome (ARDS), pulmonary embolism, barotrauma, and pulmonary edema are among the complications that can occur in patients receiving mechanical ventilation; such complications can lead to longer duration of mechanical ventilation, longer stays in the
ICU and hospital, increased healthcare costs, and increased risk of disability and death. (3) The risk of VAP is highest early in the course of hospital stay, and is estimated to be $3 \%$ per day during the first 5 days of ventilation, $2 \%$ per day during days between 5-10 of ventilation and $1 \%$ per day after this. ${ }^{(6)}$

Risk factor of VAP includes- Increases the risk of colonization by potential pathogens (e.g.- prior antibiotic therapy, contaminated ventilator circuits, decreased gastric acidity). ${ }^{(7)}$ Increased possibility of aspiration of pharyngeal contents in to the lower respiratory tract (e.g. intubation, decreased level of consciousness, presence of nasogastric tube). ${ }^{(8)}$ reduced host defence mechanism in the lung and permit overgrowth of aspirated pathogen (e.g. chronic obstructive pulmonary disease, old age, upper abdominal surgery). ${ }^{(9)}$ Clinical strategy for ventilator associated pneumonia is the presence of a new progressive radiographic infiltrates and the presence of at least two of three clinical features fever greater than $38 \mathrm{c}$, leukocytosis or leukopenia and purulent secretions represent the most accurate clinical criteria for starting empiric antibiotic therapy. This is the clinical strategy as defined by the American Thoracic Society (ATS) \& Infectious Disease Society of America (IDSA). ${ }^{(2)}$

\section{Materials and Methods}

This Study was conducted in the Department of Microbiology, Rama Medical College, Hospital \& Research Centre, Kanpur India from January 2016 to December 2016. We assessed the clinical parameters which include the history, the number of patient spent on ventilator, the timing of sample collection, clinical examination of the patient and relevant investigations. This included the blood counts, renal function tests, blood glucose, liver function tests and chest X-rays or any other relevant investigations. 


\section{Inclusion criteria}

All ICU patients admitted for more than $48 \mathrm{hrs,}$ Patients on mechanical ventilator of all age groups \& both sex were included.

\section{Exclusion criteria}

Patients already on antibiotic therapy and admitted in ICU less than 48 hrs, Patients with pneumonia prior to mechanical ventilation with Adult Respiratory, Distress Syndrome (ARDS), cavitary lung disease based on chest $\mathrm{X}$-ray findings, primary lung cancer or another malignancy metastatic to the lungs and cystic fibrosis \& Tuberculosis patients were excluded.

\section{Specimen collection}

A total of 100 Endotracheal aspirated samples were collected in a sterile \& labelled clean dry container from the clinically suspected cases of VAP patients. Specimens were transported to the laboratory as soon as possible after collection. If delay was unavoidable, the specimens was refrigerated at $4{ }^{\circ} \mathrm{C}$ to inhibit the growth of unwanted microorganisms.

\section{Specimen processing}

The Endotracheal aspirates sent to the lab were processed immediately. The samples were first subjected to Gram's staining and then quantitative cultures were performed.

The samples were inoculated on Sheep Blood agar, Chocolate agar, and MacConkey agar. All the plates were incubated for 24 to 48 hours at $37^{\circ} \mathrm{C}$. Bacterial isolates were identified by their colony characteristics \& morphology by gram's staining reaction and standard biochemical reactions. Antimicrobial susceptibility testing was performed for all the isolates with positive cultures according to Kirby-Bauer's disk diffusion method following Clinical Laboratory Standard (CLSI) Guideline 2016. ${ }^{(10)}$

\section{Results and Discussion}

Total 100 patients were included in this study who were on mechanical ventilator for more than 48 hours. Out of 100 patients 31 patients shown growth of the bacteria \& considered as Ventilator Associated Pneumonia patients. 69 patients have not shown any kind of growth of microorganisms. Out of 31 VAP patients 09 patients showed two types of bacteria so during the study we got total 40 isolates of bacteria. Acinetobacter baumanni, Pseudomonas aeruginosa, Enterobacter \& Klebsiella Pneumoniae were the most common pathogens from both early \& late onset VAP. VAP is more common in men $21(67.74 \%)$ than women $10(32.25 \%)$ in our study. The maximum cases of VAP were found in the elderly age group of 61-75 years of patients.

The administration of accurate and timely initial empirical antibiotic therapy has been shown to have a major impact on mortality from nosocomial pneumonia. Because earlyonset nosocomial pneumonia is most often reported as being due to antibiotic-sensitive pathogens, while late-onset nosocomial pneumonia is frequently caused by moreresistant pathogens, guidelines recommend monotherapy with narrow-spectrum antibiotics for early-onset infections and broad-spectrum therapy for late-onset infections. ${ }^{(14)}$ The incidence of VAP in our study was $31 \%$, which was about nearly similar to studies done by Shalini et al., $(35.78 \%)^{(15)}$ and Gadani et al., (37\%) ${ }^{(16)}$ 
Table.1 Age wise distribution of VAP cases.

\begin{tabular}{|c|c|c|c|}
\hline $\begin{array}{c}\text { Age group } \\
\text { (years) }\end{array}$ & Total $(\mathbf{n = 1 0 0 )}$ & $\begin{array}{c}\text { VAP } \\
(\mathbf{n = 3 1})\end{array}$ & $\%$ \\
\hline$<\mathbf{1 5}$ & 30 & 01 & 3.3 \\
\hline $\mathbf{1 6 - 3 0}$ & 13 & 02 & 15.3 \\
\hline $\mathbf{3 1 - 4 5}$ & 15 & 03 & 20 \\
\hline $\mathbf{4 6 - 6 0}$ & 18 & 08 & 44 \\
\hline $\mathbf{6 1 - 7 0}$ & 22 & 15 & 68.1 \\
\hline$>\mathbf{7 5}$ & 02 & 02 & 100 \\
\hline
\end{tabular}

Table.2 Showing isolates from VAP cases.

\begin{tabular}{|c|c|c|c|}
\hline S. No. & Isolated Organisms & No. of positive & \% \\
\hline $\mathbf{1}$ & Acinetobacter baumanni & 16 & 40 \\
\hline $\mathbf{2}$ & Enterobacter aerogens & 5 & 12.5 \\
\hline $\mathbf{3}$ & Pseudomonas aeruginosa & 6 & 15 \\
\hline $\mathbf{4}$ & Streptococcus pneumonia & 1 & 2.5 \\
\hline $\mathbf{5}$ & Klebsiella pneumonia & 3 & 7.5 \\
\hline $\mathbf{6}$ & MRSA & 2 & 5 \\
\hline $\mathbf{7}$ & Citrobacter freundii & 2 & 5 \\
\hline $\mathbf{8}$ & Escherichia coli & 1 & 2.5 \\
\hline $\mathbf{9}$ & Candida albicans & 1 & 2.5 \\
\hline $\mathbf{1 0}$ & Candida tropicalis & 1 & 2.5 \\
\hline $\mathbf{1 1}$ & Candida krusei & 1 & 2.5 \\
\hline $\mathbf{1 2}$ & Candida glabrata & 1 & 2.5 \\
\hline
\end{tabular}

Fig.1 Bar diagram shows Age wise distribution of VAP cases

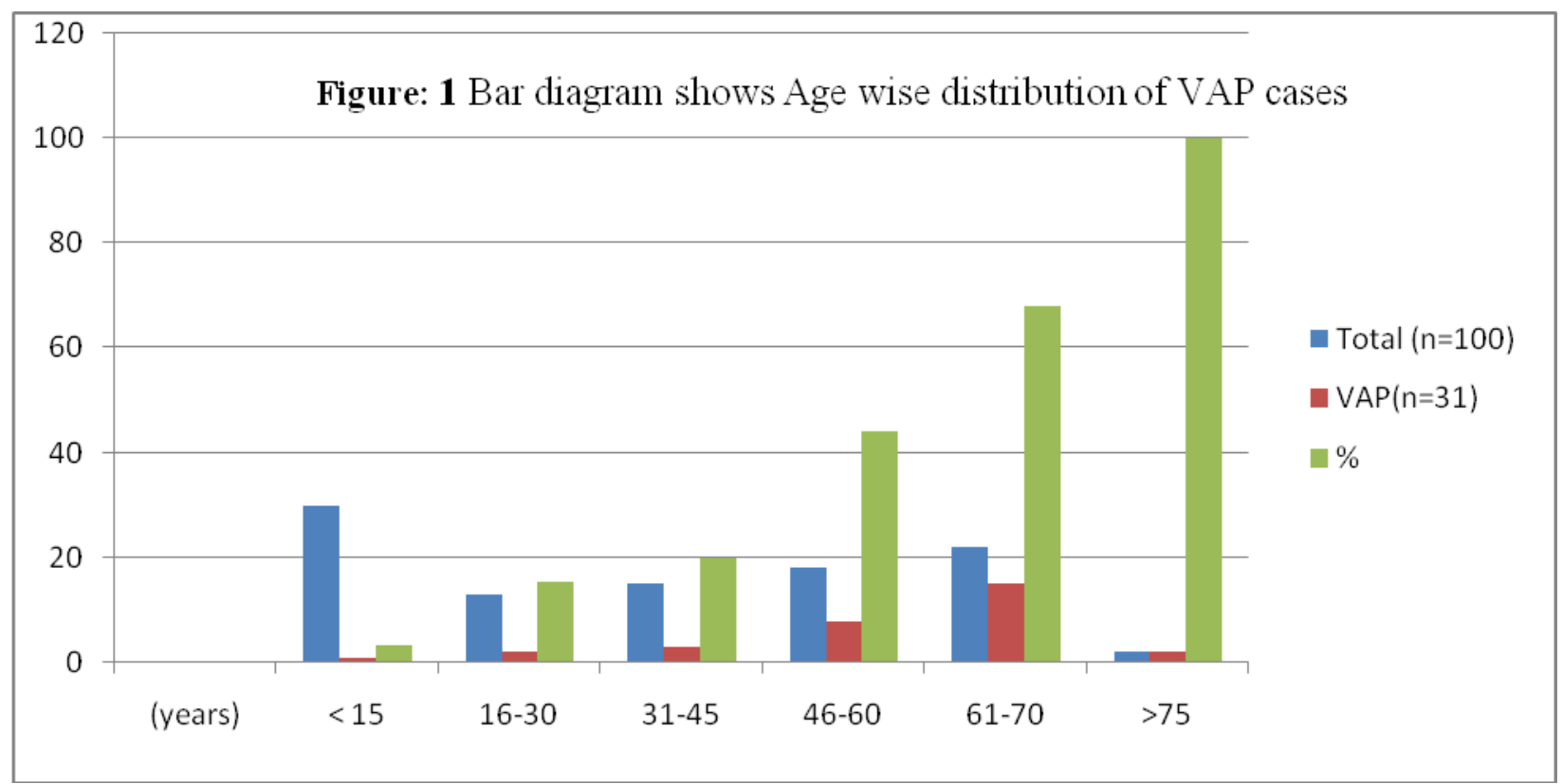


Table.3 Showing Antibiotics sensitivity Pattern of different Isolates.

\begin{tabular}{|c|c|c|c|c|c|c|c|c|c|c|c|c|c|c|c|c|}
\hline & MRP & AMC & $\mathbf{A} / \mathbf{S}$ & PIT & CTX & CTR & CFS & CPM & AK & GN & CIP & LE & TE & IMP & $\mathbf{C L}$ & PB \\
\hline Acinetobacter & 63.5 & 0 & 0 & 63.6 & 22.2 & 27.2 & 75 & 0 & 36.3 & 50 & 22.2 & 63.6 & 75 & 81.8 & 100 & 100 \\
\hline Klebsiella oxytoca & 0 & 0 & 0 & 0 & 0 & 0 & 0 & 0 & 100 & 100 & 0 & 100 & 100 & 100 & 100 & 100 \\
\hline Klebsiella pneumonae & 0 & 0 & 50 & 66.6 & 50 & 0 & 33.3 & 33.3 & 66.6 & 66.6 & 66.6 & 66.6 & 100 & 100 & 100 & 100 \\
\hline Enterobacter aerogens & 0 & 0 & 0 & 66.6 & 50 & 50 & 50 & 50 & 66.6 & 33.3 & 33.3 & 66.6 & 66.6 & 100 & 100 & 100 \\
\hline $\begin{array}{c}\text { Pseudomonas } \\
\text { aeruginosa }\end{array}$ & 60 & 0 & 0 & 100 & 0 & 0 & 50 & 50 & 100 & 100 & 100 & 100 & 0 & 100 & 100 & 100 \\
\hline Escherichia coli & 0 & 0 & 0 & 100 & 0 & 0 & 100 & 100 & 100 & 100 & 100 & 100 & 0 & 100 & 100 & 100 \\
\hline Citrobacter freundii & 0 & 0 & 0 & 100 & 0 & 0 & 100 & 0 & 100 & 100 & 0 & 100 & 100 & 100 & 100 & 1200 \\
\hline
\end{tabular}

MRP-Meropenem, AMC-Amoxicillin, A/S-Ampicillin sulbactum, PIT-Piperacillin Tazobactam, CTX-Cefoxitin, CFS-Cefoperazone sulbactam, CPM-Cefepime, AK- Amikacin, GN- Gentamicin CIP- Ciprofloxacin, LE- Levofloxacin, TE- Tetracyclline, IMP- Imipenem, CL- Colistin, PB- Polymyxin-B

Fig.2 Bar diagram Showing isolates from VAP cases

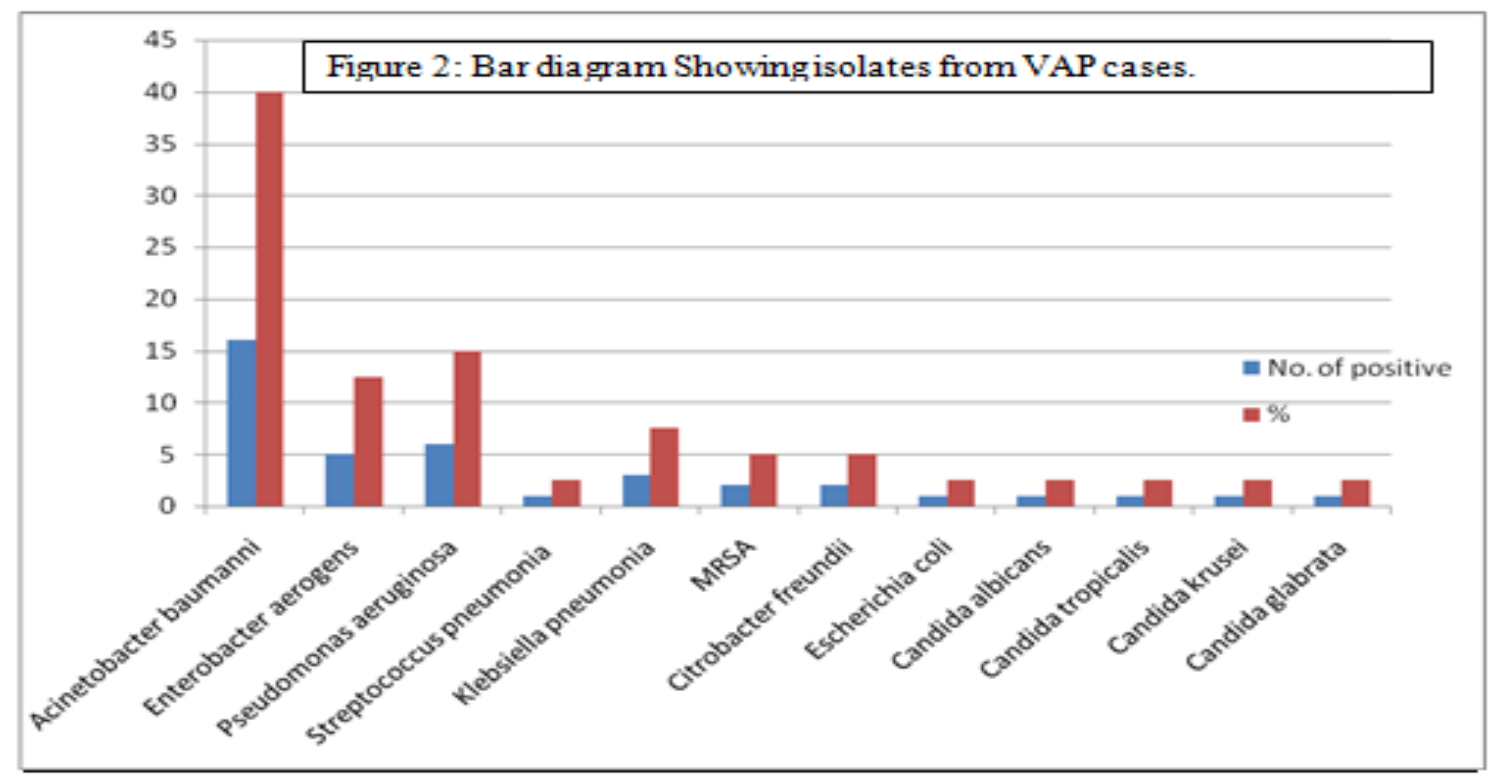


Fig.3 Distribution of early and late onset ICU

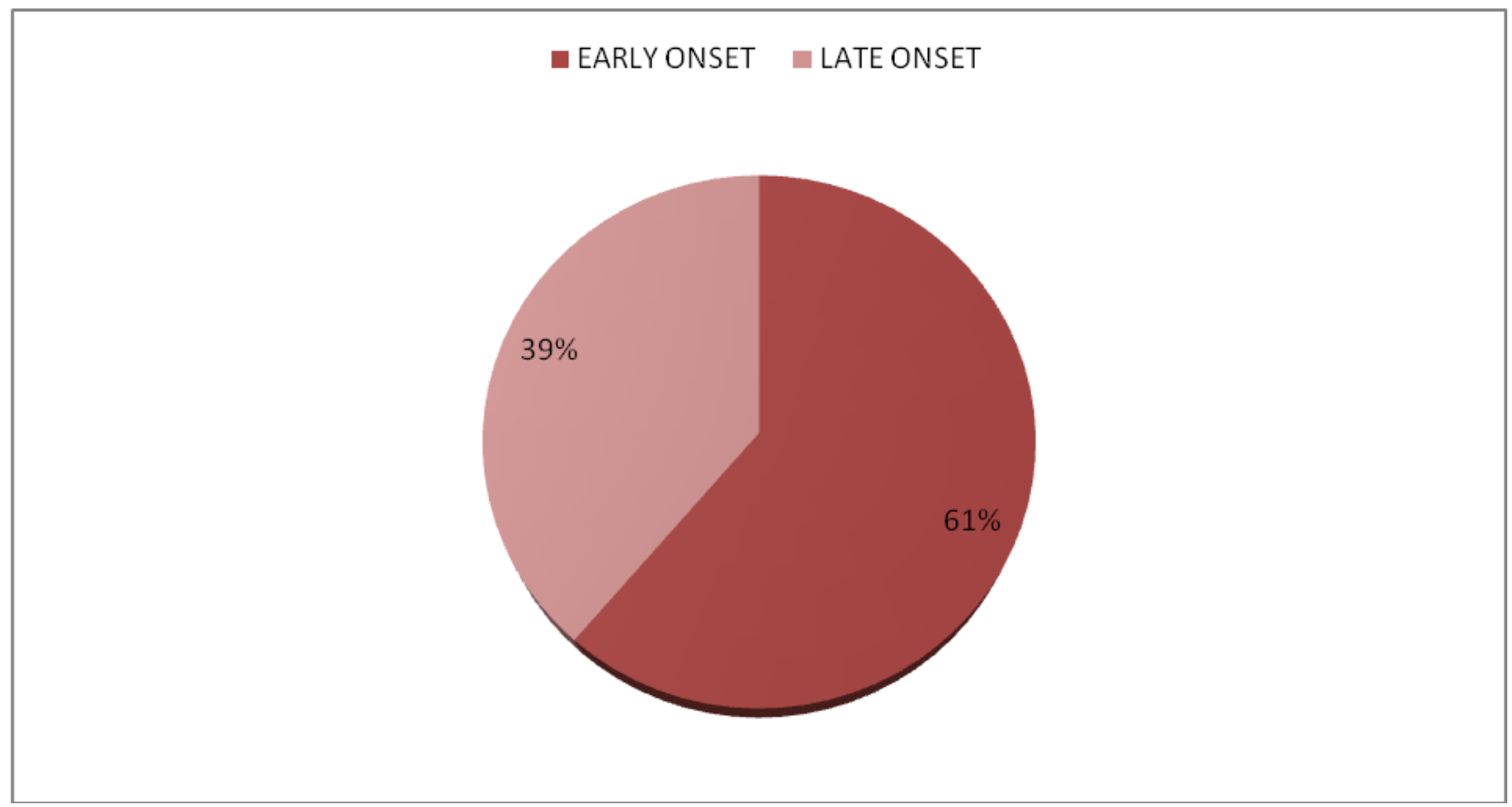

While Rajash karan et al., who reported a very high incidence rate of $73 \%{ }^{(17)} .18$ The difference in the observation by this study might be due to the variation in the duration of hospitalization prior to ventilation, prior use of antibiotics, and type of invasive procedures. Our study showed that patients in the age group of 61-75 years were more prone to VAP as the number of patients exposed to mechanical ventilation (>48hours) were also more in this age group and this was found in accordance with Jakbrittu et al., (18) The incidence of VAP was more in males $(64.51 \%)$ compared to females $(35.48 \%)$ which was similar to studies conducted by Sharma et al., ${ }^{(19)}$ Out of 31 VAP cases, $66 \%$ were categorized under early-onset VAP and $34 \%$ under late-onset VAP which was in concordance with studies conducted by Dey et al., (20) and Chastre et al., ${ }^{(13)}$ Acinetobacter baumanii (40\%) and Pseudomonas aeruginosa (15\%) were the commonest isolates obtained in both early and late onset VAP cases, which were also reported as the commonest isolates by other studies (Sharma et al., ${ }^{(19)}$, Mukhopadhyay et al., ${ }^{(21)}$ In this study, Acinetobacter baumanii (40\%), Enterobacter aerogens (12.5\%) Klebsiella pneumoniae $(7.5 \%)$ was most frequent in early-VAP cases whereas Escherichia coli $(2.5 \%)$ and Candida spp in late-VAP case.

The recent study on nosocomial pneumonia in Asia including Korea also reported that Acinetobacter species, $P$. aeruginosa, $S$. aureus, and $K$. pneumoniae were the most common pathogens identified from both early and late nosocomial pneumonia. (Chung DR et al., ${ }^{(22)}$ this study positive cocci mainly Staphylococcus aureus (MRSA $5 \%$ ) and Streptococcus pneumonia (2.5) the most frequently isolated organism in early onset VAP which is in contrast to our study.) ${ }^{(23)}$ Restrepo et al., Meropenem resistance was high in this study as $40 \%$ of the Pseudomonas and $37.5 \%$ of Acinetobacter species showed multi-drug resistance (MDR), even to carbapenems, which is in concordance with other studies. ${ }^{(24,20,25)}$ Whereas certain studies reported a lower incidence of meropenem resistance. $^{(26)} 5 \%$ of Staphylococcus aureus strains were MRSA. Among the 2 MRSA 
strains, 1 was isolated from patients with late onset VAP. The incidence of MRSA in our study correlates well with studies done by Gupta et al., ${ }^{(27)}$

The overall picture suggests that number of drug-resistant strains of various organisms is rising and is an important cause of VAP in our setting.

Therefore, this study suggests that most cases of VAP in our setting are those of late-onset VAP and a majority of these are caused by highly resistant strains and also the frequency of specific MDR pathogens causing VAP may vary by hospital, patient population, and exposure to antibiotics, type of ICU patients and changes over time, emphasizing the need for timely local surveillance data.

Early and accurate diagnosis is necessary to treat the patients in ICU. Proper monitoring and strict implementation of infection control practices is very essential to reduce VAP in hospital setting.

Also the short term use of invasive devices and judicious use of antibiotics are important in preventing VAP caused by these MDR pathogens. As for any HAI infection simple measures like hand washing, use of personal protective equipments such as gloves, face mask, and shoe cover can prevent infection thereby avoiding unnecessary use of antibiotic sand will lead to cost curtailment.

Further, it will be prudent enough if a proper antibiotic protocol is developed (keeping in consideration the prevalent microorganism and their sensitivity pattern) and followed rigidly. It will prevent the emergence of resistant strains, and many commonly used drugs can be prevented from falling into the resistant category. The clinicians and the microbiologist should work in tandem to bring about the necessary changes.

\section{References}

1.[http://www.who.int/mediacentre/factsheets/ fs331/en Updated September 2016]

2. American Thoracic Society of America: Guidelines for the management of adult with hospital-acquired, ventilator associated and healthcare-associated pneumonia. Am J RespirCrit Care Med.2005;171:388-416.

3. Centers for Disease Control and Prevention. Surveillance for ventilator associated events (http://www.cdc.gov/nhsn/acutecare-hospital/vae/index.html).

4. Trouillet $\mathrm{J}$ L. Ventilator-Associated Pneumonia: A Comprehensive Review, Hospital practice: 2012 april;40(2): 16575.

5. Early and Late Onset Pneumonia: Is This Still a Useful Classification? ${ }^{\nabla}$ PetraGastmeier 1,2,*, DoritSohr2, ChristineGeffers2, HenningRüden2, Ralf-Peter Vonberg1 and Tobias Welte3December 2016, Volume 60, Issue 12 american society for microbiology.

6. Cook D J, Walter S D, Cook R J, Griffith L $\mathrm{E}$, Guyatt $\mathrm{G} \mathrm{H}$, Leasa $\mathrm{D}$, et al., Incidence of and risk factors for ventilator-associated pneumonia in critically ill patients. Ann Intern Med. 1998;129:440.

7. Zolfaghari P S, Wyncoll D I. The tracheal tube: Gateway to ventilator associated pneumonia.Crit.Care.2011,15:310-7.

8. Lacherade J C, De Jonghe B, Guezennec P, Debbat K, Hayon J, Monsel A, et al., Intermittent subglottic secretion drainage and ventilator associated pneumonia: A multicenter trial. Am J Respire Crit Care Med.2010:182(7):910-7.

9. Safdar N, Crnich C J, Maki D G. The pathogenesis of ventilator associated pneumonia: Its relevance to developing effective strategies for prevention. 
Respir Care 2005;50:725 39.

10. CLSI - Clinical and Laboratory Standards Institute 2015. Performance standards for antimicrobial susceptibility testing. Twenty-second informational supplement. Wayne, PA, USA: CLSI: 2016;M100-S22.

11. Sharma P. C, Raut S. S, More S. R, Rathod V. S, Gujar V. M. J of evolution of med and dental sci. 2012; vol 1, issue 3:192-7.

12. Singhal. R, Mohanty S, Sood S, Das B, Kapil A. Profile of bacterial isolates from patients with ventilator associated pneumonias in a tertiary care hospital in India. Indian J Med Res. 2005;121: 6364.

13. Chastre J, Fagon J Y. Ventilatorassociated pneumonia. Am J Respir Crit Care Med. 2002;165:867 903.

14. Giard M, Lepape A, Allaouchiche B, Guerin C, Lehot J J, Robert M O, et al., Early-onset and late-onset ventilatorassociated pneumonia acquired in the intensive care unit: comparison of risk factors. J Crit Care 2008 Mar;23(1):2733.

15. Shalini S, Kranthi K, Gopalkrishna Bhat K Microbiological profile of infections in ICU. J of Clinical and Diagnostic Research 2010 4: 3109-12.

16. Gadani H, Vyas A, Kar A K. A study of ventilator-associated pneumonia: Incidence, outcome, risk factors and measures to be taken for prevention. Indian J Anaesth. 2010;54:53540.

17. Rajasekhar T, Anuradha K, Suhasini T, Lakshmi V. The role of quantitative cultures of non-bronchoscopic samples in ventilator associated pneumonia. Indian J Med Microbiol. 2006;24:10713.

18. Jakbrittu R. P, Boloor R. Characterisation of aerobic bacteria isolated from endotracheal aspirate in adult patients suspected ventilator associated pneumonia in a tertiary care center in Mangalore. Saudi J Anaesth. 2012 AprJun; 6(2): 115-19.

19. Sharma P. C, Raut S. S, More S. R, Rathod V. S, Gujar V. M. J of evolution of med and dental sci. 2012; vol 1, issue 3:192-7.

20. Dey A, Bairy I. Incidence of multidrugresistant organisms causing Ventilator associated pneumonia in a tertiary care hospital: A nine months' prospective study. Ann Thorac Med.2007;2:527.

21. Mukhopadhyay C, Bhargava A, Ayyagari A. Role of mechanical ventilation and development of multidrug resistant organisms in hospital acquired pneumonia. Indian J Med Res. 2003; 118: 229-35.

22. Chung $\mathrm{D} \mathrm{R}$, Song $\mathrm{J} \mathrm{H}$, Kim $\mathrm{S} \mathrm{H}$, Thamlikitkul V, Huang S G, Wang H, et al., High prevalence of multidrugresistant non-fermenters in hospitalacquired pneumonia in Asia. Am J Respir Crit Care Med 2011;184:140917.

23. Gastmeier P, Sohr D, Geffers C, Ruden H, Vonberg R P, Welte T. Early- and LateOnset Pneumonia: Is This Still a Useful Classification? Antimicrob Agents Chemother. 2009 July; 53(7): 2714-18.

24. Saroj Golia1, Sangeetha K. T. 2, Vasudha C. L. 3 "Microbial Profile of Early and Late Onset Ventilator Associated Pneumonia in The Intensive Care Unit of A Tertiary Care Hospital in Bangalore, India" Journal of Clinical and Diagnostic Research. 2013 Nov;Vol-7(11): 2462-2466.

25. Rahbar M, Monnavar K M, Vatan K K, Fadaei-haq A, Shakerian F. Carbapenem resistance in gram-negative bacilli isolates in an Iranian 1000-bed Tertiary Hospital. Pak J Med Sci. 2008; 24(4):537-40.

26. American Thoracic Society of America: Guidelines for the management of adult 
wih hospital-acquired, ventilator associated, and healthcare-associated pneumonia. Am J RespirCrit Care Med.2005;171:388-416.

27. Gupta A, Agrawal A, Mehrotra S, Singh
A, Malik S, Khanna A. Incidence, risk stratification, antibiogram of pathogens isolated and clinical outcome of ventilator associated pneumonia. Indian J Crit Care Med. 2011;15:96-101.

\section{How to cite this article:}

Anil Singh Yadav, R. Sujatha, Dilshad Khan, Dilshad Arif and Astha Gupta. 2021. Microbial Profile and Antibiogram of Ventilator Associated Pneumonia at Tertiary Care Hospital U.P. Int.J.Curr.Microbiol.App.Sci. 10(11): 10-18. doi: https://doi.org/10.20546/ijcmas.2021.1011.002 